\title{
Patient Expectations on How Doctors Deliver Bad News (Case Study of Cancer Patients in Jambi City)
}

\author{
Leila Mona Ganiem ${ }^{1}$, Hasanah Suryani Utami² \\ Magister Communication, MercuBuana University, Jakarta, Indonesia \\ Corresponding Author \\ Email: 1eila.mona@mercubuana.ac.id
}

\begin{abstract}
.
Research related to patient expectations has existed, but not specifically in Indonesia, especially in Jambi. For this reason, this study is aimed, firstly, to find out the patient's opinion on how doctors deliver bad news according to the SPIKES stage. The second objective was to explore patients' opinions regarding their expectations about the way doctors communicate bad news, namely cancer diagnosis and prognosis in breast cancer patients, taking into account the SPIKES protocol. This case study research uses a qualitative approach. Research in the city of Jambi in January - November 2019, used interviews with eight informants, namely female patients who saw an oncologist (cancer). Interviews were conducted with each informant and also to the group. Doctors only use some stages, namely stages, interview, giving knowledge, strategy, and summary. The patients studied think that the doctor passes through stages, perception, and invitation. There was a large tendency in the Emotions with the empathic response stage, patients who felt that they were given attention to the patient's emotional condition with an empathetic response, only a small proportion did not feel the doctor's empathic response. Expectations of patients, doctors pay attention to the stages of SPIKES as well as the dimensions of content and dimensions of relationships in delivering bad news about a diagnosis of the disease.
\end{abstract}

Keywords: patient expectations, communication of diagnosis, bad news

\section{INTRODUCTION}

Delivering bad news to patients is a difficult communication skill for doctors, although they have to experience it (Davenport \&Schopp, 2011). The way doctors deliver bad news can affect patient understanding and how they react to the conditions they experience (Liddicoat, 2018). The main problem is that doctors lack knowledge and skills in delivering bad news (Ferine, Rahayu, Claramita, 2017). Monden, Gentry, Cox's (2016) study concluded that $93 \%$ of the 54 physicians studied believed that the skills to convey bad news to patients were very important, and 7\% stated that they were important. Research from Goncalves et al (2017) of 159 family doctors in Southern Portugal, concluded that $78 \%$ of doctors felt the need to receive training on how to reveal bad news to patients. In line with that, the assessment through the CAWI- Computer Assisted Web Interview conducted by Sobczak, Leoniuk, Janaszczyk (2018) on 314 patients concluded that only $47 \%$ of patients felt comfortable with the way doctors convey bad news to them. This challenging interaction can cause problems due to differences in expectations, perceptions, and/or communication between patients and doctors (Hardavella et al, 2017). This condition is certainly not easy for both parties, so the right way is needed to bridge it. This is where communication takes a fundamental role because if the delivery of bad news about the patient's condition is not carried out properly, it can lead to conflict (Singh, 2017; Hanhe, 2019). Research by Monden, Gentry, Cox, (2016) also agrees that when the skills to convey bad news are not good enough for doctors, it can have negative consequences for patients, families, and doctors.

The skill to convey bad news is one of the skills that are consistently present in the competency standards of Indonesian doctors in 2006, 2012, and 2019 (Indonesian Medical Council, 2006, 2012, 2019). This means that an Indonesian doctor must master these communication skills. 
The bad news is defined as "any information, which adversely affects one's view of the future" (Dhage, 2017), including disease progression, prognosis, and likelihood of death. One disease that always haunts the sufferer from death and is considered bad news is breast cancer. Breast cancer is a malignant disease that occurs most frequently in women in developing countries. It is the second leading cause of death for women in the United States. In 2014 there were 232,000 new cases of women in the United States and a death toll of 40,000. In 2016 cancer is the second largest cause of death in the world, which is around $16.32 \%$, (Avryna et al, 2019).

Diagnosis of breast cancer is cancer with the highest number of new cases and deaths in Indonesia. According to the Indonesian Ministry of Health's Center for Data and Information in 2013, the number of new breast cancer cases was 819 and the number of deaths was 217, (Brilliana et al., 2017). Jambi Province ranks 13th highest, out of 34 provinces in Indonesia, and is among the 4 highest provinces in Sumatra with a cancer incidence of 1.5 per 1000 population, higher than the national average of 1.4 per 1000 population. Breast cancer cases in Jambi Province, namely in 2014 as many as 341, in 2015 as many as 240, in 2016 as many as 425 , in 2017 as many as 281 . The total number of breast cancer patients was 1,287 and had received treatment (Jambi Provincial Health Office, 2017). Cancer can occur at all ages, both men and women, although it is rare in men, which is less than $1 \%$ (Breastcancer.org, 2020). The prognosis in cancer is often at an advanced stage, the treatment takes time, the causes are multifactorial.

This dilemma situation where the doctor has to deliver bad news and the patient is forced to listen to unexpected information requires good communication skills. DiMatteo's research concludes that people's assessment of the medical profession is highly dependent on their experience with their doctors (Ganiem, 2018). Besides, the doctor's attitude and way of delivering news to patients are key elements that greatly influence the therapy that patients will undertake in the future (Sobczak, Leoniuk, Janaszczyk, 2018).

When it comes to breaking bad news to patients, doctors have several guidelines. One of them is the SPIKES protocol which was originally developed by Robert Buckman (Davenport \&Schopp, 2011). The SPIKES protocol which continues to develop with creative modifications in the medical community is often used to discuss difficult news for patients (Baile, Buckman, Lenzi, Glober, Beale, Kudelka, 2000). Researchers believe that the protocol in SPIKES considers two important elements in communication, namely the content dimension and the relationship dimension (Littlejohn \& Foss, 2018).

Doctors are medicine for patients (Bar-haim, 2018). The importance of having a doctor who can communicate effectively with patients and growing patient strength in facing the difficult conditions they experience is an ideal condition that is expected. A study in Portugal (Goncalves et al., 2017) can open up because this study places the doctor's position in a professional role and when the doctor is a patient. The results concluded that physicians felt that worry because the delivery of diagnosis (determination of disease) and prognosis (prediction of disease progression) had an adverse psychological impact and influenced patient expectations, but gave the patient a chance to have control over the situation. However, when a lifethreatening situation occurs to the doctor himself, most doctors want to know the diagnosis and prognosis and participate in making treatment decisions.

Research related to patient expectations has existed, but not specifically in Indonesia, especially in Jambi. For this reason, this study is aimed, firstly, to find out the patient's opinion about how doctors deliver bad news according to the SPIKES stage. The second objective was to explore patients' opinions regarding their expectations about the way doctors communicate bad news, namely cancer diagnosis and prognosis in breast cancer patients, taking into account the SPIKES protocol.

\section{LITERATURE REVIEW}

\section{Axioms: Content Dimensions and Relationship Dimensions}

Referring to the theory developed by Paul Watzlawick (in Griffin et al, 2019) that the relationships in a family system are interdependent and very difficult to change. In general, axioms or rules are considered facts or truths that can be accepted in communicating. According to Watzlawick, there are four axioms. The 
first is that one cannot but communicate. Second, communication consists of content and relationships. Third, the nature of the relationship depends on how the two parties interpret the communication chain. Fourth, all communication is symmetrical or complementary interaction. Although the concept of interpersonal communication from Watzlawick focuses on family, in this study, we believe, the concept can be useful for various contexts, including health contexts. For that, we take advantage of the important concept that communication consists of a content dimension and a relationship dimension.

Researchers used interactional view theory and focused only on the second point of the rules mentioned, namely communication consisting of content or content dimensions and relationship dimensions. Content can be interpreted as what is said or related to the content of the message conveyed. Meanwhile, a relationship or relationship can be defined as how the message is conveyed or related to how it is conveyed.

The delivery of information on this condition should be conveyed with the right choice of technique and an empathic approach will affect the effectiveness of receiving the news to the patient. There are several techniques for delivering bad news that has been developed among health practitioners, including the ABCDE model developed by Rabow and McPhee in 1999. This model elaborates on A-advance preparation. B, build a therapeutic environment/relationship. C, communicate well. D, deal with patient and family reactions. E, encourage and validate emotions (Monden, Gentry \& Cox, 2016; Singh \& Agarwal, 2017).

In addition to the ABCDE model, there are also SPIKES guidelines or protocols (Baile et al., 2000; Davenport \&Schopp, 2011, Rachmat\& Ganiem, 2020). The SPIKES protocol consists of six steps, namely:

Table 1: SPIKES protocol

\begin{tabular}{|c|c|c|}
\hline No & Stages & Explanation \\
\hline 1 & $\begin{array}{l}\text { (S) Settingup the } \\
\text { interview }\end{array}$ & $\begin{array}{l}\text { The initial stage of the doctor prepares for the delivery of } \\
\text { bad news, starting from preparing the room conditions, } \\
\text { the position of the patient, the need for the patient to be } \\
\text { accompanied, and establishing an atmosphere before the } \\
\text { information is conveyed. }\end{array}$ \\
\hline 2 & $\begin{array}{l}\text { (P) Assessing the } \\
\text { patient'sPercepti } \\
\text { on }\end{array}$ & $\begin{array}{l}\text { The doctor tries to find out the patient's view of his } \\
\text { condition. In this activity, what can be done is, the doctor } \\
\text { should ask the patient's understanding of the condition and } \\
\text { disease. Regarding the disease, if there is a mistake in the } \\
\text { patient's understanding and information about the disease, } \\
\text { the doctor can make corrections, so that the patient has a } \\
\text { correct understanding. }\end{array}$ \\
\hline 3 & $\begin{array}{l}\text { (I) Obtaining the } \\
\text { patient'sInvitatio } \\
n\end{array}$ & $\begin{array}{l}\text { In this stage, the doctor can explore the patient's desire for } \\
\text { the information he wants. The doctor can ask the extent to } \\
\text { which the patient wants to be explained about the disease. } \\
\text { informed about the diagnosis, prognosis, and treatment } \\
\text { options available, it will be easier for the doctor to convey } \\
\text { the bad news. When the patient states explicitly that he or } \\
\text { she wants to hear the information in detail or only } \\
\text { important matters. }\end{array}$ \\
\hline 4 & $\begin{array}{l}\text { (K) } \\
\text { GivingKnowledge } \\
\text { and information } \\
\text { tothepatient }\end{array}$ & $\begin{array}{l}\text { At this stage, the doctor conveys medical facts with good } \\
\text { knowledge to the patient. Providing information can be } \\
\text { started from what the patient understands and needs, as } \\
\text { expressed by the patient at the Perception and Invitation } \\
\text { stages. }\end{array}$ \\
\hline 5 & $\begin{array}{l}\text { (E) Addressing } \\
\text { the } \\
\text { patient'sEmotion }\end{array}$ & $\begin{array}{l}\text { At this stage, the patient will respond to bad news that he } \\
\text { heard from the doctor. The patient's response varies from } \\
\text { silence, anger, disbelief, crying or resistance, and }\end{array}$ \\
\hline
\end{tabular}




\begin{tabular}{|c|l|l|}
\hline $\begin{array}{l}\text { swith empathic } \\
\text { responses }\end{array}$ & $\begin{array}{l}\text { withdrawal. The doctor must be able to show empathy in } \\
\text { responding to the patient's emotions. Doctors must be able } \\
\text { to provide empathetic support to patients. }\end{array}$ \\
\hline $\mathbf{6}$ & $\begin{array}{l}\text { S) } \\
\text { StrategyandSum }\end{array}$ & $\begin{array}{l}\text { This stage is to determine the next action on the patient. } \\
\text { This stage is not solely the doctor's decision, but the } \\
\text { patient and his family must be involved in making the } \\
\text { decision. The doctor should convey and discuss the } \\
\text { treatment options and prognosis to the patient before the } \\
\text { patient decides what to do with him. }\end{array}$ \\
\hline
\end{tabular}

Some of the previous studies are also interesting to note.

Before setting up the interview, the clinic or hospital has conducted various operational activities regarding data of patients either manually or using technology (Fajriah, Oktantyo, 2020). The study entitled "Changing Communication Needs and Preferences Across the Cancer Care Trajectory: Insights from the Patient Perspective" conducted by Thorne et al. (2014), who looked at the communication needs of cancer patients and changes in preferences along the course of their disease illustrates that patients appreciate doctors' efforts to indicates individual sensitivity. Patients are also very happy when doctors treat him like a human who has a right to life even though he has cancer. What makes communication around decisionmaking about cancer management effective from the patient's perspective is the doctor's responsiveness to the patient's emotional needs. Some of the patients stated, "They liked it when the doctor answered their questions but did not need more explanation because of the pressure they felt after hearing the doctor's explanation."

The next study conducted by Dhage et al, (2017), "Breaking bad news of cancer diagnosis - the patient's perspective" explores the patient's perspective in receiving cancer news and their expectations. The results of this study indicate that all patients want their relatives to be with them when the bad news is conveyed to them. Regarding the use of guidelines in delivering bad news, according to the patients, it was found that $15 \%$ of doctors did not greet patients, $10 \%$ of patients were suddenly reported, while $99 \%$ of doctors did not explain any positive aspects of the disease-related to treatment outcome. Patients also shared that doctors do not ask patients about the need for an explanation of the diagnosis and they do not speak a language the patient can understand. Therefore, the suggestion from the researchers in this study is to suggest that doctors apply the protocol in conveying the bad news of cancer diagnosis to patients.

Another study is about preferences or something that cancer patients in Malaysia prefer in obtaining information related to bad news (Eng et al, 2012). In this study, it was concluded that nine items were considered important patients, namely: doctors are expected to be honest about the severity of the patient's condition, the doctor explains the treatment options in detail, explains the best treatment options, delivers all the different treatment options, the doctor is up to date on the type of cancer suffered by the patient, the doctor is also asked to deliver directly, provides detailed information about the medical test results, is notified personally, and convey hope about his illness. In this study it was also conveyed that Malaysians wanted doctors' honesty in delivering bad news, this is different from the general perception that Asian patients should be protected in delivering bad news, for fear that they will not be able to cope (Huang et al., 1999. Lapine et al., 2001).

Doctors' problems when delivering bad news are raised in a scientific paper entitled "Breaking Bad News In Clinical Setting: A Systematic Review" written by Singh, et al. 2017. For doctors, delivering bad news is not an easy thing. This study outlines several guidelines that can be used to deliver bad news, advises doctors to use protocols in delivering bad news, including SPIKES which is designed for doctors to deliver bad news at certain stages. In a similar study conducted by Hahne, 2019, doctors described the desire for more skills training to assess patient psychology in the communication process. 


\section{METHODS}

This case study research uses a qualitative approach as an effort to understand subjective reality, especially understanding patient expectations of doctors in delivering bad news to patients, which in this case is cancer.

This research was conducted in the city of Jambi in January - November 2019, on eight informants, namely female patients who saw an oncologist (cancer). Patients aged 40-65 years, with minimum education from high school to university, and have been diagnosed with cancer with varying initial duration of diagnosis. Researchers know there is a group of cancer patients who all undergo treatment at the oncology poly of a hospital in Jambi. The researcher submitted a request to the group members to be interviewed. Eight subjects were willing to become informants for a total duration of five months. All informants were interviewed individually and in groups twice. Based on the agreement, for ethics to keep patient secrets, during the interview process with informants, researchers did not take pictures, only recorded conversations during the interview. Researchers also recorded important information, especially nonverbal during the interview process.

The criteria of the informants are 1) patients who have been diagnosed with breast cancer. Consideration of breast cancer because this disease is the most common cancer in Indonesia (WHO, 2018), 2) female informants because although there are men who have breast cancer, it is mostly experienced by women. Besides that, women tend to be more willing to share stories because researchers are also women, 3). Willing to share experiences about his hopes for doctors when doctors deliver bad news about the disease the informant is experiencing.

In this study, researchers used a voice recorder to record the things stated by the informants, so that it could make it easier for researchers to repeat the results of interviews conducted and minimize the loss of information from the informants. The in-depth interview process is very important in data collection. The data collected from informants was explored in depth until it reached saturation. Extracting data proposed in the study used a semi-structured format referring to the SPIKES protocol (Baile, 2000), namely the preparation of the doctor at the initial interview, the doctor's efforts to understand the patient's views and conditions, extracting the patient's desires, conveying information from doctor to patient, the doctor's reaction to the response. emotional patient, the stage of determining the next action. Although the SPIKES protocol is for physicians, the researchers used these guidelines as a reference in understanding the stages that patients go through in exploring patient expectations for what doctors convey to them.

The interviewer is the first writer who has a medical professional so that he understands the process in the protocol to convey bad news to patients. Meanwhile, the process of making interviews and data analysis was carried out together with the second author who has experience in the field of medical communication. The atmosphere of the interview with the patient was carried out in a comfortable time and place. The interview duration for each informant ranged from 30 minutes to 60 minutes. Group interviews were conducted with four informants. All data collected were transcribed and then confirmed to the informants to ascertain whether they were written as conveyed by the informants.

Data analysis refers to Miles and Huberman, (2014), which starts from data collection, then reduces it by simplifying and summarizing and coding the data categorically, then presenting the data in a chart and matrix, then drawing conclusions and verifying it with a discussion. look at the findings.

\section{RESULT AND DISCUSSION}

From extracting data on informants regarding their opinions on how doctors deliver bad news from diagnosis to prognosis referring to the SPIKES protocol, the following information can be obtained:

According to the patient, doctors do not use the stages of delivering bad news as suggested in the complete SPIKES protocol, namely, 1) setting the interview, 2) assessing the patient's perception, 3) obtaining the patient's invitation, 4) giving knowledge and information to the patient, 5) addressing the patient's emotions with empathic responses, and 6) strategy and summary. 
The doctor only uses some of these stages, namely the stage 1) setting the interview, which is the initial stage where the doctor prepares for the delivery of bad news, starting from preparing the room conditions, the position of the patient, the patient's need for accompanied, and building an atmosphere before the information is conveyed. Stage 4) giving knowledge and information to the patient, which is the stage where the doctor delivers medical facts with good knowledge to the patient by providing information after a question from the patient or something the patient needs. Another stage that is passed is stage 6) strategy and summary, namely the stages of determining the next step on the patient. At this stage, the doctor allows the patient and family to be involved in making decisions. The doctor communicates and discusses the treatment options and prognosis to the patient before the patient decides what to do with him. Eventhough in its use the informant tended to state that it was not optimal as stated in the following statements;

Stage 1) setting the interview.

The statement states that this stage is not optimal as stated by the following Informant 2: "Read for a while, he said directly, "This needs surgery ma'am"."

Informants who feel that this stage is carried out quite well, such as the following statement, Informant 6: "The doctor is very good at calming, "Be patient, we will try as much as we can"." Informant 7:"The doctor said like this, "How are you, ma'am, it's getting fresher"."

Stage 4) giving knowledge and information to the patient.

The statement of the informant who felt that this stage was not optimal as conveyed by the following Informant 5: "I want to be explained in detail, there is no doctor, we get a lot of information from outside, the internet or friends."

Informants who felt that this stage was carried out as conveyed by Informant 7: "The doctor is not troublesome, he is fine, joking too, if we ask, he will answer, he explained."

Stage 6) strategy and summary.

The statement of the informant who felt that this stage was not optimal, as conveyed by Informant 2: "The agreement does not exist, he who decides, this is not offered."

The informant felt that this stage was carried out as Informant 4 stated: "Ma'am, this must be removed because this is malignant because it is read from the lab results, many are taken and then healthy, do not be afraid to throw them away so that they do not spread, after that we do chemo." "Doc, do I have to do chemo?" "Yes, to kill cancer cells." "For alternative decisions, he did not explain, he explained the surgery after that we did chemo 6 times."

Patients in this study tend to feel that the doctor skip stage 2) assessing the patient's perception, or the stage where doctors try to find out the patient's view of the condition and disease. Because there was no such elaboration effort, there was no attempt to find misunderstanding and misinformation of the patient about his disease. Then the doctor did not make corrections that make the patient had a correct understanding. Stage 3) obtaining the patient's invitation, or a stage that the doctor can use to determine the patient's wishes and needs to be explained about his disease. The informant said this was because the number of patients was quite large so that doctors did not have enough time to carry out the steps according to the guidelines for delivering bad news (SPIKES Guide).

Some of the following statements from the informant represent Stage 2 of assessing the patient's perception which is not treated by doctors according to the informants, such as the following statements, Informant 1: "Iwas immediately ordered to have a surgery, I didn't want to, I had a hunch that an alternative can cure me". The second informant: "He said my disease was malignant, stage 3, but I couldn't think that if this ismalignant, I didn't feel sick."

In stage 3) obtaining the patient's invitation, all informants stated that the doctor did not do it, as conveyed by the following informants. Informant 1: "At the first one it was immediately ordered to have the surgery, there was not explained, anyway it must be the surgery. The second informant: "He (doctor) immediately said about having a surgery". Informant 3: "He didn't ask, I asked." Informant 4: "I think it's enough because at that time my mind was down so I didn't want to be explained anything." Informant 5: "We 
want to be explained in detail because this is a deadly disease, not a mild disease. He should have conveyed it, but he has a lot of patients.. The Informant 6: "The point is we get it from the outside, we feel unethical too if it is detailed, instead of doctors wanting us to think for ourselves, if we are asked, he will answer."

Regarding stage 5)Addressing the patient's Emotions with empathic responses, there is a tendency that most patients claim that doctors pay attention to the patient's emotional condition with an empathetic response, only a small proportion do not feel the doctor's empathic response.

Some informants stated that the doctor paid attention to him from the side of his emotions such as the following statement. Informant 3:"Are you not afraid of surgery? That's good, youare great." Informant 4:"It's okay, many people are taken and stay healthy, don't be afraid, the doctor is smiling, even though his face looks tired but it's still a good way of conveying that makes us calm." Informant 5: "He showed concern about the condition, it's okay, if you have money, it will be quickly taken, ma'am." Informant 6: "He made me calm, be patient, ma'am, we are trying our best, the doctor is great, the doctor is attentive, like this (thumbs up), especially if we seem to feel sick." Informant 7:"He also wanted to please the patient, he said I look young." Informant 8:"Spoke softly, wanted to joke. Be patient, we will treat it."

Meanwhile, the informants who felt that the doctor did not do it optimally stated, as follows, Informant 1:"He's really serious, look at the results, don't see the person.'Informant 2: "I'm not scared but I'm sure it's not that hard,this doctor was unfriendly."

Furthermore, regarding the patient's expectations on how doctors communicate in delivering bad news to cancer patients in the city of Jambi, the concept of guidance for delivering bad news SPIKES according to the patient's point of view is as follows:

Patients' expectations on the doctor's way of communicating bad news in the early stages of the meeting (setting) or preparation, namely, patients tend to want the doctor to convey it in a friendly way, for example with a soft and not fierce smile. Besides, it does not make the patient feel more down or afraid. The patient also hopes that the doctor must be able to calm the patient. Also, patients want the doctor to be attentive, and occasionally use jokes and praise sentences, or in a more relaxed way. Both verbally, non-verbally, and the information.

The patient's expectation of the doctor's communication method in exploring the patient's perception of bad news about his disease is that patients want doctors to listen and respond to what they say about their disease. Some other informants wanted them to be active in asking questions. Some focus on their condition, others focus on what action they want.

The patient's expectation on the doctor's way of communication in exploring the desire (Invitation) and conveying the depth of bad news information about the disease or the patient's need to be explained about bad news is several. Some informants want to be explained clearly in full, in detail, the cause and effect of the disease. However, some only want to be briefly explained, only the points they consider important for them to know.

The patient's expectation for the doctor's communication method in providing knowledge when delivering bad news (knowledge) of his disease is following their respective expressions in the previous stage, namely the perception invitation stage.

The patient's expectation on the doctor's way of communication in helping to manage patient emotions when delivering bad news is that they want the doctor to calm down, the doctor listens more.

Patients' expectations on the doctor's way of communication when discussing determining actions for bad news (Strategy \& Summary) tend to be that they want the doctor to convey what they said at the invitation stage, and hope the doctor will explain some options for action. Meanwhile, there was a tendency for other informants to leave to the doctor what action to take next for their condition.

\section{Discussion}

Delivering bad news is a complex communication task, Baile et al. (2000); Singh, et al (2017); Torres, (2018). In addition to the doctor-patient relationship, attention to illness, health, suffering, and uncertainty is 
also an important part, not only the verbal component, other skills are needed, including responding to patient emotional reactions, involving patients in decision making, dealing with stress created by the patient's hope for recovery, the involvement of several family members, and the dilemma of how to give hope when the situation worsens.

The patient's expectations must be a concern for the doctor so that the goal of doctor-patient communication can be accomplished. The patient's expectation is the patient's or customer's belief before trying or obtaining a product or service that is used as a standard or reference in assessing the performance of the product or service (Tjiptono, 2000). Patients' expectations should be detected early on if doctors use an interview guide, which can help doctors speed up the communication process without destroying the doctorpatient relationship due to patient dissatisfaction (Baile, 2000).

The SPIKES guide that is used when delivering bad news can be used as an effort to identify patient expectations at each stage of SPIKES. The not optimal use of the SPIKES stage guide in this study resulted in a large amount of information in the form of patient expectations or wishes that were overlooked by doctors. The not optimal use of SPIKES in this study can be seen from the results of patient confirmation at each stage. Doctors in this study only used some stages, namely the setting, knowledge, strategy, and skip other stages, namely the perception stage and the invitation stage. At the stage of emotion, informants tend to feel it, but not all. Quantitative research was also carried out by Marschollek, Bakowska, Bakowski, Marschollek, Tarkowski (2019) and also conducted on 226 cancer patients in Poland. The results do not appear to be too different from this study. That is, the patient feels at the stage of setting up the interview (the doctor prepares to deliver bad news), knowledge (the doctor delivers medical facts with good knowledge to the patient), emotions (the doctor can show empathy in responding to the patient's emotions after responding to the bad news he hears). Regarding the strategy \& summary (namely the stages in determining the next action for the patient), at this stage the patient's perception of doctors in Jambi was quite good, in Poland it was also quite good, at $56.9 \%$. What's interesting is that regarding Perception and invitation, patients in both countries feel that doctors don't pay enough attention.

The stages that doctors do not take are no less important than the other stages. At this stage, the doctor can understand what the patient's perception is like about his disease and the stages that the doctor can use to find out the patient's wants and needs to be explained about the disease.

The patient's expectations for the doctor's way of delivering bad news in this study were expressed in various terms by the informants. Informants tend to want doctors to convey in a friendly way, meaning with a smile, gentle, not fierce, do not make them feel more afraid, calm, convey attentively or interspersed with jokes and praise, as conveyed by informants $4,5,6,7,8$. or in a more relaxed way or enjoy using Informant 3's language, not too serious in Informant 1's language, not sadistic or not too straightforward (Informant 2). The expectation of the next patient is related to the doctor's explanation of the disease, namely the informant's tendency to want to be explained in detail, including a causal relationship, while some others only want to be explained the points, the important things, and only what he wants to know.

When it's viewed from the communication dimension approach, the informant's statement describes the desired communication dimension. From the content dimension, some want more content dimensions, while others want the opposite. From the dimension of the relationship, the tendency that the patient or patient informants want is a humane way of conveying information to him.

High patient expectations for more humane services have changed the role of doctors who were previously dominant, patriarchal, asymmetrical in providing services, into patient-centered care (PCC) (Ganiem, 2018: 78). According to Kurzt (1998), in medicine there are two communication approaches used:

1. Disease-centered communication style or doctor-centered communication style. Communication is based on the doctor's interest in making a diagnosis, including investigation and clinical reasoning about signs and symptoms. 
2. Illness-centered communication style or patient-centered communication style. Communicationbased on how the patient feels about his or her illness is individually a unique experience. This includes the patient's opinion, concern, hope, what is his interest, and what he thinks (Ali et al ed, 2006).

In this study, there was a tendency for doctors to still use the doctor-centered communication style approach, although a small proportion used the patient-centered approach. According to the researchers, this seems to be based on the doctor's observations of each patient. The different characters and perceptions of patients in interpreting the actual treatment by doctors cause the reluctance of doctors to interact more deeply with these patients so that doctors tend to return to a communication approach that is oriented towards the doctor's interests, which is related to clinical matters.

This patient-centered approach has long been used in developed countries, so it is not surprising that we often hear many patients claiming to be more comfortable seeking treatment and interacting with doctors abroad, as stated in a study conducted by Benjamin Inge, 2014, entitled "Tracing the Flow of Health Checks and Medication Abroad", which states the various reasons for medical treatment abroad, among them, are not from our bad treatment, but, better service, more professional impression, more friendly, disciplined, and faster according to what expected.

This more humanist approach to communication is supported by the concept of communication, which has two dimensions, namely the content dimension and the relationship dimension (Devito in Ganiem, 2018: 29). The content dimension is the message conveyed, while the relationship dimension is the interaction that occurs which involves emotions in communication (Ganiem, 2018: 29). The content dimension shows the content or content of communication or what is said, while the relationship dimension shows how to say which also indicates how the relationship between communication participants. The content dimension was mostly coded verbally, while the relationship dimension was coded non-verbally (Mulyana, 2002).

To communicate effectively, these two dimensions cannot be ignored or we cannot choose one of them (Ganiem, 2018: 29). In this study, it is seen that these two dimensions influence each other. When the content is not as expected, but conveyed well, (the dimension of the relationship is maintained), the message content can still be received well, while if the message does not match expectations and is delivered in a way that the patient does not expect, the message content becomes difficult received by the patient. This occurs in patients who put forward more relationship dimensions. While the patient is more concerned with the content of the message, when the message does not match his expectations, the relationship with the doctor becomes affected, he becomes lazy to listen to the doctor's next statement and further results in rejection of the doctor's explanation.

It can be said that the context of the content and relationship dimensions is different between patients, even though in this study it was found that the relationship dimension saved doctors from patient disappointment. The relationship dimension helps the patient to try to accept even in uncomfortable conditions. A study in South China entitled "Effects of Doctor-patient Communication on Quality of Life among Breast Cancer Patients in Southern China" states, patients who accept a good attitude or have a good relationship with their doctors, have a higher quality of life, socially, emotional, functional than patients who experience bad attitudes from their doctors (Zhou et al, 2014).

In this study, the informants also argued that doctors could not complete the SPIKES stage because doctors did not have sufficient time, considering that many patients had to be served. The same results were also obtained in previous research conducted by Sobczak et al in Poland, patients also complained that time was a problem (Sobczak et al, 2018). Although Kurtz (1998) states that effective communication does not take long and is proven to require less time because doctors are skilled at recognizing the needs of patients who do not only need to be cured, (Ali et al, ed. 2006).

The time problem which is said to be the reason for the barrier for patients to get a doctor's explanation in this study cannot be quantified by patients when it is confirmed by the investigators on them. 
Each has a different portion of time and definition. The tendency of them stated that they will feel that the time is considered sufficient, when each time they ask, the doctor gives an answer that they can understand, or when there are no more questions they want to ask. This means that it may take less or more time depending on the quality of the conversation that occurs according to the expectations of each patient. When doctors can understand how much each one needs for information, then time should no longer be a problem, because everyone has their portion, as Kurtz (1998) calls effective communication (Ali et al, 2006).

The doctor's ability to understand the expectations, interests, worries, and needs of patients, or patient-centered care, should make the interaction time effective (Kurtz in KKI, 2006). Successful communication between doctors and patients will generally result in comfort and satisfaction for both parties.

\section{CONCLUSION}

The SPIKES guide that is used when delivering bad news can be used as an effort to identify patient expectations at each stage of SPIKES. The not optimal use of the SPIKES stage guide in this study resulted in a large amount of information in the form of patient expectations or wishes that were overlooked by doctors.

Patients' expectations for the doctor's way of communicating bad news about a cancer diagnosis in breast cancer patients in Jambi City in 2019 are as follows; In the setting stage, the patient tends to want to be conveyed, namely, the patient tends to want the doctor to convey in a friendly way, for example with a soft and not fierce smile. Besides, it does not make the patient feel more down, or afraid. So the doctor must be able to calm the patient. Also, it is expected that doctors must be attentive, and occasionally use jokes and praise sentences, or in a more relaxed way. Both verbally, non-verbally, and the information.

The patient's expectation of the cancer doctor's communication method in exploring the patient's perception of bad news is that patients want doctors to listen to and respond to what they say about their disease. Some other informants prefer those who actively ask questions, some focus on what action it wants. The informant wants to be explained.

The patient's expectations on the doctor's way of communication in knowing (invitation) the desire for the depth of information to be explained to him, namely the doctor asking the patient. Some want to be explained clearly in full, in detail, the cause and effect of their disease, some want to be briefly explained, the points they consider important for them to know, some want more content dimensions, while others have only a few relationship dimensions is more important.

The patient's expectation on the doctor's way of communicating at the stage of providing knowledge or (knowledge), the patient wants what is said in the invitation stage.

The patient's expectation of the doctor's way of communication at this stage helps manage emotions. They want the doctor to calm down, listen more. The patient's expectation on the doctor's way of communication at the Strategy \& Summary stage, as mentioned in the invitation stage, provides options. The tendency of other informants to submit to the doctor. This study has limited informants to patients who are only willing to be known and tell their illness, so information is limited. In conveying bad news to patients, doctors should pay attention to the readiness and expectations of the patient for the information to be conveyed. Doctors must pay attention to the patient's condition, try to multiply patient knowledge, pay attention to patient expectations, by giving or providing time to communicate, show empathy, show good expressions, provide complete information including alternatives, provide support for patient decisions and use sentences and words that easily understood by the patient. The patient's expectations can be detected from the stage of the bad news delivery guide that can be used by doctors, one of them is using SPIKES. Humanist service involves both dimensions of communication and mutual influence. When the content does not match expectations but is conveyed well, (the dimension of the relationship is maintained), the message content can still be received well, while if the message content does not match expectations and is delivered in a way that the patient does not expect, the message content becomes difficult. received by patients, so these two dimensions of communication need to be considered by doctors when delivering bad news from a diagnosis. 
Doctor services need to be patient-oriented if it refers to a condition that the patient is a unique individual so that it cannot be treated the same, even though it can be grouped. Because of this uniqueness, the easiest way is to ask the patient what his expectations are from the doctor's way of explaining the bad news to him so that the patient willingly takes action according to the doctor's advice and there is a satisfactory therapeutic relationship.

\section{REFERENCES}

1. Ali, M. M., Sidi, I. P. S., \&Zahir, H (2006). Komunikasi Efektif Dokter Pasien. Jakarta: Konsil Kedokteran Indonesia.

2. Avryna, P., Wahid, I.,\&Fauzar, F.(2019). Invasive Carcinoma Mammae dengan Metastasis Orbita, Tulang, dan Paru. Andalas Journal of Health, 8(15). Retrieved from https://doi.org/10.25077/ jka.v8i1S.932.

3. Arafah, A. B. R., \& Notobroto, H. B. (2017).Faktor yang Berhubungan dengan Perilaku Ibu Rumah Tangga Melakukan Pemeriksaan Payudara Sendiri (Sadari). The Indonesian Journal of Public Health, 12(2). Retrieved from http://dx.doi.org/10.20473/ijph.v12i2.2017.143-153.

4. Baile, W. F., Buckman, R., Lenzi, R., Glober, G., Beale, E. A., \&Kudelka, A.P. (2000). SPIKES-A six-step protocol for delivering bad news: application to the patient with cancer. Oncologist, 5(4), 302-11. Retrieved from https://doi.org/10.1634/theoncologist.5-4-302.

5. Balint, M. (1964). The Doctor, His Patient and The Illness. London:Pittman Medical.

6. Bar-Haim, S. (2018). 'The Drug Doctor': Michael Balint and the Revival of General Practice in Postwar Britain, History Workshop Journal, 86 (Autumn 2018), 114-132. Retrieved from https://doi.org/10.1093/hwj/dby017.

7. Benjamin, I. W.(2014).Menelusuri Arus Pemeriksaan Kesehatan dan Pengobatan ke Luar Negeri.Jurnal Widya Medika Surabaya, 2(1). Retrieved from https://oi.org/10.33508/ jwm.v2i1.1646.

8. Breastcancer.org. (2020). Male Breast Cancer. Retrieved from https://www.breastcancer. org/symptoms/types/male_bc.

9. Buckman, R. (1992). How to Break Bad News. Baltimore, MD: Johns Hopkins University Press.

10. Davenport., L, \&Schopp, G. (2011) Breaking bad news: communication skills for difficult conversations. JAAPA, 24(2), 46-50. Retrieved from https://doi.org/10.1097/01720610-201102000-00008.

11. DiMatteo, M. R. (1998). The role of the physician in the emerging health care environment. Western Journal of Medicine. 168(5), 328-333. Retrieved from https://www.ncbi.nlm.nih.gov/pmc/articles /PMC1304975/.

12. DeVito, J. A., (2019). The Interpersonal Communication Book. New York: Pearson.

13. Dhage, A. S.,\&Wilkinson, A. R. (2017).Breaking bad news of cancer diagnosis the patient's perspective. International Journal of Research in Medical Sciences,5(4), 1617-1621.Retrieved from https://dx.doi.org/10.18203/2320-6012.ijrms20171275.

14. Dinas Kesehatan Provinsi Jambi. (2018). Profil Kesehatan Provinsi Jambi 2017. Jambi: Pemerintah Provinsi Jambi.

15. Eng, T. C., Yaakup, H., Shah, S. A., Jaffar, A., \&Omar, K. (2012). Preferences of Malaysian cancer patients in communication of bad news. Asian Pacific Journal of Cancer Prevention. 13(6), 2749-52. Retrieved from https://doi.org/10.7314/apjcp.2012.13.6.2749

16. Fajriah, Riri., Oktantyo, Dwi Putra Bayu. (2020) Analisa dan PerancanganPelayananPasienBerbasis Web pada KlinikDokter Bersama di Kembangan. Jukomika - (JurnalIlmuKomputer dan Informatika) Volume 3, Nomor 2, April 2020;P-ISSN: 2655-755X https://jurnal.ikhafi.or.id/index.php/jukomika/ 315

17. Ferine, F., Rahayu, G. R., \&Claramita, M. (2017). Identifying Doctors Problems in Breaking Bad News: An Initial Step in Developing Recommendations for the Curriculum. The Indonesian Journal of Medical Education, 6(2), 108-115. Retrieved from https://jurnal.ugm.ac.id/jpki/article/view/32255/ 19473.

18. Ganiem, L.M. (2018).Komunikasi Kedokteran: Konteks Teoritis dan Praktis. Jakarta: PenerbitPrenada.

19. Griffin, E. A. (2011). A first look at communication theory 8th ed. New York: McGraw-Hill.

20. Hahne, J., Liang, T., Khoshnood, K., Wang, X., \& Li, X. (2020). Breaking bad news about cancer in China: Concerns and conflicts faced by doctors deciding whether to inform patients. Patient Education and Counseling, 103(2). Retrieved from https://doi.org/10.1016/j.pec.2019.08.022.

21. Hardavella, G., Aamli-Gaagnat, A., Saad, N., Rousalova, I., \&Sreter, K. B. (2017). How to give and receive iscepifeedback effectively. Breathe (Sheffield, England), 13(4), 327-333. Retrieved from https://doi.org/10.1183/20734735.009917

22. Konsil Kedokteran Indonesia, (2006). Standar Kompetensi Dokter Indonesia. Jakarta: Konsil Kedokteran Indonesia 
23. KonsilKedokteran Indonesia, (2012). StandarKompetensiDokter Indonesia. Jakarta: KonsilKedokteran Indonesia

24. KonsilKedokteran Indonesia, (2019). Standar Nasional Pendidikan Profesi Dokter Indonesia. Jakarta: KonsilKedokteran Indonesia

25. Kurtz, S., Silverman, J. \&Drapper, J. (1998). Teaching and Learning Communication Skillsin Medicine. Oxon: Radcliffe Medical Press.

26. Lapine, A., Wang-Cheng, R., Goldstein, M., Nooney, A., Lamb, G., \&Derse, A. (2001). When Cultures Clash: Physician, Patient, and Family Wishes in Truth Disclosure for Dying Patients. Journal of Palliative Medicine, 4(4),475-80. Retrieved from https://doi.org/10.1089/109662101753381610.

27. Liddicoat, P. (2018). Breaking bad news. InnovAiT, 11(12), 671-675. Retrieve from https://doi.org/10.1177/1755738018797963.

28. Littlejohn, S. W., \& Foss, K. A.(2018). TeoriKomunikasi: Theories of Human Communication. Jakarta: Salemba Humanika.

29. Marschollek P, Bąkowska K, Bąkowski W, Marschollek K, Tarkowski R. Oncologists and Breaking Bad NewsFrom the Informed Patients' Point of View. The Evaluation of the SPIKES Protocol Implementation. J Cancer Educ. 2019 Apr; 34(2):375-380. doi: 10.1007/s13187-017-1315-3. PMID: 29399734.

30. Miles, M. B., Huberman, A. M., \&Saldana, J. (2014). Qualitative Data Analysis, Los Angeeles: SAGE Publishing.

31. Monden, K. R., Gentry, L., \& Cox, T. R. (2016). Delivering bad news to patients.Proceedings (Baylor University. Medical Center),29(1), 101-102. Retrieved from https://doi.org/10.1080/08998280.2016.11929380.

32. Mulyana, D., (2002). Ilmu Komunikasi Suatu Pengantar. Bandung: RemajaRosdakarya.

33. Rabow, M.W., \&McPhee, S. J. (1999). Beyond breaking bad news: how to help patients who suffer.Western Journalof Medicine, 171(4), 260-263. Retrieved from https:/www. ncbi.nlm.nih.gov/pmc/issues/124809/

34. Rachmat, Dara \& Ganiem, Leila. (2020). TahapanKomunikasiTerapeutikDokter pada Pasien di KlinikKecantikan. JurnalKomunikasi Global. 9. 61-79. 10.24815/jkg.v9i1.16107.

35. Singh, M. M., \&Agarwal, R. K. (2017). Breaking Bad News InClinical Setting: A Systematic Review.Indian Journal of Applied Research, 8(12), 29-32. Retrieved from https://www.worldwidejournals.com/indian-journal-ofapplied-research-(IJAR)/fileview/ December_2017_1512116815_11.pdf.

36. Sobczak, K., Leoniuk, K., \&Janaszczyk, A. (2018). Delivering bad news: patient's perspective and opinions. Patient Preference and Adherence, 12, 2397-2404. Retrieved from https://doi.org/10.2147/PPA.S183106

37. Thorne, S., Hislop, T. G., Kim-Sing, C., Oglov, V., Oliffe, J. L., \&Stajduhar, K. I. (2014). Changing communication needs and preferences across the cancer care trajectory: insights from the patient perspective. Support Care Cancer, 22(4), 1009-1015. Retrieved from https://doi.org/10.1007/s00520-013-2056-4.

38. Tjiptono, F. (2000). Manajemen Jasa. Yogyakarta: Penerbit Andi

39. Torres, A. R., Soto, E. C. J., Patiño, D. C. (2018). Medical consultation, time and duration, Medwave, 18(5). Retrieved from https://doi.org/10.5867/medwave.2018.05.7264.

40. Widowati, H. (2019). Berbagai Kasus Kanker di Indonesia 2018. Databoks. Retrieved from https:/databoks.katadata.co.id/datapublish/2019/06/03/kasus-kanker-payudara-paling-banyak-terjadi-di-indonesia.

41. Zhou, Q., Shen, J., Liu, Y., Lin, G., Dong, H., \&Li, K. (2014). Effects of Doctor-patient Communication on Quality of Life among Breast Cancer Patients in Southern China. Asian Pacific Journal of Cancer Prevention, 15(14), 5639-44. Retrieved from https://doi.org/10.7314/apjcp. 2014.15.14.5639. 